Discussion Paper No. 983

\title{
STRATEGIC PERILS \\ OF OUTSOURCING: \\ SOURCING STRATEGY \\ AND PRODUCT POSITIONING
}

\author{
Noriaki Matsushima \\ Cong Pan
}

October 2016

The Institute of Social and Economic Research

Osaka University

6-1 Mihogaoka, Ibaraki, Osaka 567-0047, Japan 


\title{
Strategic Perils of Outsourcing: Sourcing Strategy and Product Positioning*
}

\author{
Noriaki Matsushima $^{\dagger}$ \\ Institute of Social and Economic Research, Osaka University \\ Cong $\operatorname{Pan}^{\ddagger}$ \\ Graduate School of Economics, Osaka University.
}

October 25, 2016

\begin{abstract}
Although outsourcing input production has long been considered as an important approach to help downstream manufacturers enhance structural efficiency, we provide a theoretical explanation for why outsourcing may negatively affect downstream firms' profitability. We consider a duopoly model wherein downstream manufacturers endogenously determine their input sourcing and product positioning strategies. We show that when inputs from outside suppliers are not perfectly compatible with downstream manufacturers' requests, outsourcing causes downstream manufacturers to pursue aggressive product positioning behavior, leading to the prisoner's dilemma - even though both downstream manufacturers could be better off producing inputs in-house, they may still choose outsourcing.
\end{abstract}

JEL classifications code: C72, L13, M31.

Keywords: Outsourcing; Product differentiation; Suppliers; Hotelling model.

\footnotetext{
${ }^{*}$ We gratefully acknowledge financial support from JSPS KAKENHI Grant Numbers JP15H03349 and JP15H05728, Grant-in-Aid for JSPS Fellows Grant Number JP15J05223, and the program of the Joint Usage/Research Center for Behavioral Economics at ISER, Osaka University. The usual disclaimer applies.

${ }^{\dagger}$ Noriaki Matsushima, Institute of Social and Economic Research, Osaka University, Mihogaoka 6-1, Ibaraki, Osaka 567-0047, Japan. Phone: (81)-6-6879-8571. Fax: (81)-6-6879-8583. E-mail: nmatsush@iser.osakau.ac.jp

${ }^{\ddagger}$ Corresponding author: Cong Pan, Graduate School of Economics, Osaka University, Machikaneyama 1-7, Toyonaka, Osaka 560-0043, Japan. Phone: (81)-6-6850-6111. Fax: (81)-6-6850-5205. E-mail: pge042pc@student.econ.osaka-u.ac.jp.
} 


\section{Introduction}

Outsourcing inputs has long been an important part of manufacturing. In general, it brings downstream manufacturers a trade-off between avoiding fixed costs of holding their own input facilities and incurring wholesale prices offered by outside suppliers (e.g., Shy and Stenbacka, 2003; Xiao et al., 2014; Liu and Tyagi, 2016). That is, outsourcing has a trade-off between eliminating fixed cost and adding marginal costs. In addition, compared with insourcing, outsourcing helps downstream manufacturers save resources for producing inputs, and thus, helps them concentrate better on quality control, although this happens at the cost of procuring inputs (Xiao et al., 2014). ${ }^{1}$ That is, outsourcing also has a trade-off between a higher quality and a poorer procuring condition.

By taking into account the above trade-offs, we also consider the interdependence between a downstream manufacturer's product positioning and sourcing strategies (Novak and Eppinger, 2001; Ulrich and Ellison, 2005). Product positioning, which is related to product differentiation, always involves specific knowledge and/or knowhow. It is possible that outsourcing puts a downstream manufacturer with high product distinctiveness at a disadvantage because of the growing difficulty in finding a suitable outside input supplier. To investigate this matter, we employ a simple Hotelling model that enables us to discuss the relation between downstream manufacturers' product positioning and sourcing strategies. ${ }^{2}$ We consider a duopoly case wherein downstream manufacturers endogenously determine sourcing strategies by anticipating the following decisions on product positioning represented by their locations along a linear city. That is, they determine their sourcing strategies, anticipating

\footnotetext{
${ }^{1}$ For example, Techtronic Industries (TTI), a leading investment holding company whose products include well-known brands like Milwaukee, AEG, Ryobi, Homelite, Hoover US, Dirt Devil, and Vax, outsources its production to external suppliers, and focuses on product design and other specifications in-house (Zhu et al., 2007). For additional information on theoretical demonstrations, see Grossman and Helpman (2002).

${ }^{2}$ As in related theoretical papers, firms' product positioning strategies are captured by locations along the Hotelling line (Tyagi, 2000, 2001; Guo, 2006; Kim and Serfes, 2006; Meza and Tombak, 2009; Sajeesh and Raju, 2010; Liu and Tyagi, 2011; Sajeesh, 2016). Also see papers in the marketing context (e.g., Hauser, 1988; Moorthy, 1988; Desai, 2001; Kuksov, 2004; Xiang and Sarvary, 2007; Zhang, 2011).
} 
the subsequent location choices in the Hotelling line. Two upstream firms, whose locations are exogenously given at each edge on the linear city, engage in price competition for the downstream business. Each upstream firm incurs a per unit transportation cost to supply its input to a downstream manufacturer. This transportation cost reflects an adjustment cost to meet the request made by a downstream manufacturer. When a downstream manufacturer chooses outsourcing, it procures inputs from the upstream firm that offers the lowest input price for it. ${ }^{3}$

As noted, outsourcing inputs enables a downstream manufacturer to focus on quality control, leading to more premium final products than those under insourcing. ${ }^{4}$ In the absence of outsourcing, because downstream manufacturers do not procure inputs from the outside, their product characteristics do not affect the cost structures. Thus, manufacturers make products that are sufficiently differentiated to alleviate the downstream competition. When outsourcing is employed, on the other hand, the product positioning of an outsourcing downstream manufacturer affects the wholesale price charged by the trading upstream firm. In reality, the wholesale price is determined by the per unit cost of the upstream firm, which does not supply to this outsourcing downstream manufacturer as in the standard Bertrand competition. Compared with the location under insourcing, the downstream manufacturer tends to locate geographically closer to the less compatible upstream firm under outsourcing in order to create a better outside option for itself, and it procures inputs at a lower wholesale price. Thus, the downstream price competition becomes more intense. When only one downstream manufacturer chooses outsourcing, it can enlarge demand by offering premium

\footnotetext{
${ }^{3}$ In the theoretical context of vertical integration and separation, Matsushima $(2004,2009)$ considers similar settings in the sense that downstream firms determine their locations while upstream firms engage in price competition in the Hotelling line. However, Matsushima (2004, 2009) restricts downstream firms' locations to the line segment, while the present study considers the location problem along the whole line. Besides, Matsushima $(2004,2009)$ assesses whether a downstream firm's choice on vertical structure (integration/separation) is based on the joint profits of the downstream and its pairing upstream firms, while in our case, a downstream firm decides whether to outsource by evaluating its own profit change only.

4 As an extension of the main model, we also consider another possible benefit of outsourcingeliminating/reducing fixed costs necessary for input production.
} 
final products and locating at a good position and thus obtains better profits than the other firm choosing insourcing. However, when both downstream manufacturers outsource their input production, the relative advantage in their final products' quality no longer exists, and only the losses from intensified price competition remain. Therefore, our analysis generates a counterintuitive result: outsourcing may bring no benefits and only losses. More specifically, although both downstream manufacturers are better off by insourcing input production, they may still choose outsourcing.

Our results have important managerial implications in firms' sourcing strategies. Until now, large numbers of real-world cases have described outsourcing to be a beneficial management strategy from two points of view: converting fixed cost to variable cost and chasing high-quality input products. ${ }^{5}$ However, researchers have paid scant attention to a quite general situation in vertical relations, namely, one where the intermediate products supplied by an upstream firm are not perfectly compatible with the downstream firms' requests. In some industries, in order to supply different downstream manufacturers, an input supplier always has to develop a basic product model, which is then customized for a particular manufacturer. ${ }^{6}$ Our study shows the dark side of outsourcing, namely that, in the presence of such imperfect compatibility, downstream manufacturers sometimes coordinate themselves to produce inputs independently regardless of the supposed benefits of outsourcing.

Downstream manufacturers' sourcing strategies have received considerable attention from the theoretical aspect. To capture players' strategic incentives, some studies have endogenized producers' sourcing patterns and have obtained results similar to ours in the sense that three types of sourcing outcomes can exist in equilibrium — none, either, or both producers outsource

\footnotetext{
${ }^{5}$ Liu and Tyagi (2016) list many real-world cases wherein outsourcing helps manufacturers save fixed costs. Zhu et al. (2007) summarize examples about how outsourcing boosts quality-improvement efforts in supply chains.

${ }^{6}$ An example of this type can easily be found in the aircraft and automobile industries (Ahmadjian and Lincoln, 2001; Bonaccorsi and Giuri, 2001). Needless to say, economists have also theoretically focused on the imperfect compatibility of inputs in vertically related industries (e.g., Eaton and Schmitt, 1994; Norman and Thisse, 1999; Matsushima, 2004, 2009).
} 
their input production (e.g., Shy and Stenbacka, 2003; Gilbert et al., 2006; Xiao et al., 2014; Liu and Tyagi, 2016). In these studies, however, as long as the output producer chooses outsourcing in equilibrium, it always benefits from either a better procurement condition or more premium outputs. Our finding contrasts with such results by showing that even if both output producers' outsourcing may exist in equilibrium, both of them lose benefits.

Liu and Tyagi's (2011) research is closely related to our study as their research motivation also stems from how production positioning affects producers' sourcing strategies. However, Liu and Tyagi (2011) model each upstream firm as an exclusive supplier, so that the inputs are perfectly compatible for each downstream manufacturer. The downstream manufacturer who chooses outsourcing tends to further differentiate its products from its rival's so as to alleviate double marginalization. The resultant downstream price competition is so relaxed that in equilibrium, both downstream manufacturers always outsource their input production. Our study considers the imperfect compatibility of inputs so that outsourcing results in less differentiation in final products and more intense downstream price competition. Thus, owing to the difference in the sourcing environment, our study shows contrasting results and adds several new insights to the existing literature. ${ }^{7}$

The remaining paper is organized as follows. Section 2 explains the model. Section 3 shows the main result. Section 4 briefly discusses the extension of the model. Section 5 concludes the paper.

\section{The Model}

There are two downstream firms, $D_{1}$ and $D_{2}$, competing in a linear city wherein consumers are uniformly distributed along the interval $[-1 / 2,1 / 2]$ and with a mass of 1 . Each downstream firm, $D_{i}$, is located at $l_{i} \in(-\infty, \infty)(i=1,2)$. A consumer living at $y \in[-1 / 2,1 / 2]$ incurs a transportation cost of $t\left(l_{i}-y\right)^{2}$ when purchasing a product from $D_{i}$. The consumers have

\footnotetext{
${ }^{7}$ Although Marjit and Mukherjee (2008) show a similar result, namely that outsourcing creates the prisoner's dilemma, their definition of "outsourcing" differs from ours. In that study, outsourcing is defined as an investment for marginal cost reduction and thus involves no structural change in the supply chain.
} 
unit demands; that is, each consumer purchases either one or zero units of the product. Each consumer derives a surplus from consumption (gross of price and transportation costs) equal to $v+e_{i}$ when purchasing a product from $D_{i}(i=1,2)$, where $v$ is the benefit from the basic characteristics of each product, and $e_{i}$ is the product quality of $D_{i}$. Let $v$ be large enough such that every consumer gains positive utility from purchasing. Two upstream firms, $U_{A}$ and $U_{B}$, supply inputs to the downstream market with no production costs. For simplicity, we assume that $U_{A}\left(\right.$ resp. $\left.U_{B}\right)$ is exogenously fixed at point $-1 / 2\left(\right.$ resp. 1/2). When $U_{A}\left(\right.$ resp. $\left.U_{B}\right)$ supplies one unit of input to $D_{i}, U_{A}\left(\right.$ resp. $\left.U_{B}\right)$ incurs a transportation cost, $\tau\left(-1 / 2-l_{i}\right)^{2}$ (resp. $\left.\tau\left(1 / 2-l_{i}\right)^{2}\right){ }^{8}$

We assume that each downstream firm can determine whether (i) it procures inputs from either upstream firm, $U_{j}(j=A, B)$, at an input price, $w_{i j}$, and produces final products with high quality $\left(e_{i}=\alpha t(>0)\right.$ under outsourcing), or (ii) it produces inputs by itself at no cost, and produces final products with low quality $\left(e_{i}=0\right.$ under insourcing). The assumption captures a scenario in which vertical decentralization benefits the decentralized downstream firm, because it can concentrate on its retail activities and improve its product quality (Grossman and Helpman, 2002). ${ }^{9}$

Following Liu and Tyagi (2011), we set the time line of the game as follows. In the first stage, the downstream firms simultaneously decide their sourcing patterns - either an outsourcing one or an insourcing one. If both downstream firms choose insourcing, the upstream firms are driven out of the market. In the second stage, the downstream firms simultaneously decide their locations. In the third stage, if at least one downstream firm chooses outsourcing, each upstream firm, $U_{j}$, simultaneously offers its input prices, $w_{i j} \in[0, \infty)$, to the outsourcing downstream firm(s), $D_{i}$. The upstream firms engage in price competition for the downstream business. If both downstream firms choose insourcing, the game skips to the last stage. In the

\footnotetext{
${ }^{8}$ Matsushima $(2004,2009)$ does not assume the quality advantage of a downstream firm even under outsourcing (a vertically separated downstream firm in his models).

${ }^{9}$ In the context of outsourcing, Grossman and Helpman (2002) explain why decentralized downstream firms have some advantages with regard to efficiency and/or quality.
} 
last stage, the downstream firms set their prices $p_{i} \in[0, \infty)$ simultaneously, and the demand is created.

\section{Results}

Hereafter, we use the superscripts " $i i$," "oo," and "oi" to denote the three types of subgames respectively: "Insourcing-Insourcing," "Outsourcing-Outsourcing," and "OutsourcingInsourcing."

Before deriving the equilibrium outcome in each subgame, we first derive the marginal consumer who is indifferent between purchasing from $D_{1}$ and $D_{2}:{ }^{10}$

$$
x\left(p_{1}, p_{2}, l_{1}, l_{2}, e_{1}, e_{2}\right)=\frac{l_{1}+l_{2}}{2}+\frac{p_{2}-p_{1}+e_{1}-e_{2}}{2 t\left(l_{2}-l_{1}\right)} .
$$

Thus, the demand faced by firm $1, Q_{1}$, and that faced by firm $2, Q_{2}$, are given by

$$
\begin{aligned}
& Q_{1}\left(p_{1}, p_{2}, l_{1}, l_{2}, e_{1}, e_{2}\right)=\min \left\{\max \left(x\left(p_{1}, p_{2}, l_{1}, l_{2}, e_{1}, e_{2}\right)+1 / 2,0\right), 1\right\}, \\
& Q_{2}\left(p_{1}, p_{2}, l_{1}, l_{2}, e_{1}, e_{2}\right)=1-Q_{1}\left(p_{1}, p_{2}, l_{1}, l_{2}, e_{1}, e_{2}\right) .
\end{aligned}
$$

We set the assumption seen below and define the following symbol to simplify the expositions of the outcomes in lemmas and propositions:

Assumption $1 \tau$ is not large enough. Concretely,

$$
\mu \equiv \tau / t<3(4 \sqrt{2}-5) / 2 \simeq 0.985
$$

This inequality in Assumption 1 is needed for the existence of equilibrium in the subsequent discussion. Besides, we also need Assumption 2 to guarantee that each type of sourcing outcome exists in equilibrium:

Assumption 2 The quality enhancement from outsourcing is not too large. Concretely,

$$
\alpha<0.129 \text {. }
$$

If $\alpha$ is too large, at least one of the downstream firms will choose outsourcing, and thus the " $i i$ " type sourcing outcome fails to exist.

\footnotetext{
${ }^{10}$ Equation (1) is derived using equation $v+e_{1}-t\left(l_{1}-x\right)^{2}-p_{1}=v+e_{2}-t\left(l_{2}-x\right)^{2}-p_{2}$.
} 


\subsection{The Outsourcing-Insourcing Case}

Without losing generality, we consider the case that $D_{1}$ chooses outsourcing, while $D_{2}$ chooses insourcing.

In the last stage, the downstream firm $i$ decides its price by solving the following optimization problem:

$$
\begin{aligned}
& \max _{p_{1}} \pi_{1}^{o i}\left(p_{1}, p_{2}, l_{1}, l_{2}, w_{1}\right) \equiv\left(p_{1}-w_{1}\right) Q_{1}\left(p_{1}, p_{2}, l_{1}, l_{2}, \alpha t, 0\right), \\
& \max _{p_{2}} \pi_{2}^{o i}\left(p_{1}, p_{2}, l_{1}, l_{2}\right) \equiv p_{2} Q_{2}\left(p_{1}, p_{2}, l_{1}, l_{2}, \alpha t, 0\right) .
\end{aligned}
$$

The equilibrium prices are as follows:

$$
\begin{aligned}
& p_{1}^{o i}\left(l_{1}, l_{2}, w_{1}\right)=\frac{2 w_{1}+e+\left(l_{2}-l_{1}\right)\left(3+l_{1}+l_{2}\right) t}{3} \\
& p_{2}^{o i}\left(l_{1}, l_{2}, w_{1}\right)=\frac{w_{1}-e+\left(l_{2}-l_{1}\right)\left(3-l_{1}-l_{2}\right) t}{3} .
\end{aligned}
$$

In the third stage, the upstream firms engage in price competition for only $D_{1}$. The conditions in Assumption 1 and Assumption 2 guarantee that the location of $D_{1}$ is always on the left-hand side of the center $\left(l_{1}<0\right)$. Thus, $U_{1}$ wins the Bertrand competition with a wholesale price

$$
w_{1}^{o i}=\tau\left(1 / 2-l_{1}\right)^{2}
$$

which is the transportation cost of $U_{2}$.

Substituting equations (5), (6), and (7) into equations (3) and (4), we obtain the maximization problems of the downstream firms in the second stage:

$$
\begin{aligned}
& \max _{l_{1}} \pi_{1}^{o i}\left(l_{1}, l_{2}\right)=\frac{\left[\alpha t-\tau\left(1 / 2-l_{1}\right)^{2}+t\left(l_{2}-l_{1}\right)\left(3+l_{1}+l_{2}\right)\right]^{2}}{18\left(l_{2}-l_{1}\right) t}, \\
& \max _{l_{2}} \pi_{2}^{o i}\left(l_{1}, l_{2}\right)=\frac{\left[\tau\left(1 / 2-l_{1}\right)^{2}-\alpha t+t\left(l_{2}-l_{1}\right)\left(3-l_{1}-l_{2}\right)\right]^{2}}{18\left(l_{2}-l_{1}\right) t} .
\end{aligned}
$$

Solving the first-order conditions, we derive the following lemma: 
Lemma 1 When one downstream firm chooses outsourcing and the other one chooses insourcing, the following location pattern is an equilibrium outcome:

$$
\begin{aligned}
& l_{1}^{o i}=\frac{-3-4 \mu+3 \mu^{2}+H}{6 \mu(1+\mu)}, l_{2}^{o i}=\frac{-3+5 \mu+H}{6 \mu}, \\
& \text { where } H \equiv \sqrt{9-(3-12 \alpha) \mu+(4+12 \alpha) \mu^{2}} .
\end{aligned}
$$

At the equilibrium outcome, each firm's profit is

$$
\begin{aligned}
\pi_{1}^{o i} & =\frac{\left[-9+(21+12 \alpha) \mu+(14+12 \alpha) \mu^{2}+(3+7 \mu) H\right]^{2} t}{243 \mu^{2}(1+\mu)(6+2 \mu+H)} \\
\pi_{2}^{o i} & =\frac{\left[9+(33-12 \alpha) \mu+(4-12 \alpha) \mu^{2}-(3-2 \mu) H\right]^{2} t}{243 \mu^{2}(1+\mu)(6+2 \mu+H)}
\end{aligned}
$$

The profit when $\alpha=0$ and $\mu=0$ is $\left.\pi_{1}^{o i}\right|_{\alpha=0, \mu=0}=\left.\pi_{2}^{o i}\right|_{\alpha=0, \mu=0}=3 / 4$.

A simple comparison between $\pi_{1}^{o i}$ and $\pi_{1}^{o i}$ leads to the following proposition:

Proposition 1 For any $\mu$ and $\alpha, \pi_{1}^{o i}>\pi_{2}^{o i}$. That is, the profit of the outsourcing downstream firm is relatively higher than that of the insourcing downstream firm.

Proof: $\quad$ The difference between $\pi_{1}^{o i}$ and $\pi_{2}^{o i}$ is given as

$$
\begin{aligned}
\pi_{1}^{o i}-\pi_{2}^{o i} & =\frac{\left(24 \mu(1+\mu) \alpha-2\left(9+6 \mu-5 \mu^{2}\right)+(6+5 \mu) H\right) t}{27 \mu(1+\mu)} \\
& >\frac{\left(-2\left(9+6 \mu-5 \mu^{2}\right)+(6+5 \mu) \sqrt{9-3 \mu+4 \mu^{2}}\right) t}{27 \mu(1+\mu)}>0 .
\end{aligned}
$$

The first inequality is derived by setting $\alpha=0$ because $\partial\left(\pi_{1}^{o i}-\pi_{2}^{o i}\right) / \partial \alpha>0$. The second inequality is derived by the following comparison: $\left((6+5 \mu) \sqrt{9-3 \mu+4 \mu^{2}}\right)^{2}-(2(9+6 \mu-$ $\left.\left.5 \mu^{2}\right)\right)^{2}=405(1+\mu) \mu^{2}>0$.

Q.E.D.

The outsourcing firm has an incentive to move toward the center to reduce its input price $w_{1}^{o i}$ in (7). Anticipating the incentive of the outsourcing firm, the insourcing firm locates far away from the center. In fact, $\left|l_{2}^{o i}\right|>\left|l_{1}^{o i}\right|$ (see Lemma 1). Note that in standard Hotelling models, it is quite well-known that a downstream firm's quality advantage is equivalent with its cost advantage. Here, even though the quality adjusted marginal cost of the outsourcing 
firm, $w_{1}^{o i}-\alpha t$, is higher than that of the insourcing firm, zero, the location advantage of the former firm dominates its cost disadvantage. ${ }^{11}$ As a result, the outsourcing firm earns a relatively higher profit than the insourcing firm. Notice that $l_{2}^{o i}>1 / 2$, implying that $D_{1}$ 's outsourcing forces $D_{2}$ to locate out of the line segment. This fact follows from our assumption that downstream firms can locate along the whole line, not necessarily within the line segment. As in Matsushima (2004, 2009), if downstream firms' locations are restricted within the line segment, $D_{1}$ 's outsourcing would then cause $D_{2}$ 's location at the end point, $1 / 2$. If this is the case, Proposition 1 holds only when $\mu<\alpha$. Because both downstream firms locate at the end points, the outsourcing firm does not have location advantage over the insourcing one. Hence, the outsourcing firm achieves a higher profit only when its quality advantage is sufficiently high. In our case, Proposition 1 stems from a different mechanism because it is independent of $\mu$ and $\alpha$.

One might consider that outsourcing is better than insourcing when product positioning matters because of the relative profitability of outsourcing in Proposition 1. However, as discussed in the following subsections, outsourcing can appear as a result of the prisoner's dilemma.

\subsection{The Outsourcing-Outsourcing Case}

In the last stage, the downstream firm, $i$, decides its price by solving the following optimization problem:

$$
\max _{p_{i}} \pi_{i}^{o o}\left(p_{1}, p_{2}, l_{1}, l_{2}, w_{1}, w_{2}\right) \equiv\left(p_{i}-w_{i}\right) Q_{i}\left(p_{1}, p_{2}, l_{1}, l_{2}, \alpha t, \alpha t\right) .
$$

The wholesale price, $w_{i}$, is determined through price competition between the upstream firms, $w_{i}=\min \left\{w_{i A}, w_{i B}\right\}$. The equilibrium prices are as follows:

$$
\begin{aligned}
& p_{1}^{o o}\left(l_{1}, l_{2}, w_{1}, w_{2}\right)=\frac{\left(l_{2}-l_{1}\right)\left(3+l_{1}+l_{2}\right) t+2 w_{1}+w_{2}}{3}, \\
& p_{2}^{o o}\left(l_{1}, l_{2}, w_{1}, w_{2}\right)=\frac{\left(l_{2}-l_{1}\right)\left(3-l_{1}-l_{2}\right) t+w_{1}+2 w_{2}}{3} .
\end{aligned}
$$

\footnotetext{
${ }^{11}$ Because Proposition 1 holds for any positive $\alpha, w_{1}^{o i}-\alpha t$ is larger than zero when $\alpha$ is quite small.
} 
Substituting $p_{i}\left(l_{1}, l_{2}, w_{1}, w_{2}\right)$ in (13) and (14) into Equation (12), we obtain

$$
\begin{aligned}
& \pi_{1}^{o o}\left(l_{1}, l_{2}, w_{1}, w_{2}\right)=\frac{\left[\left(l_{2}-l_{1}\right)\left(3+l_{1}+l_{2}\right) t-w_{1}+w_{2}\right]^{2}}{18\left(l_{2}-l_{1}\right) t} \\
& \pi_{2}^{o o}\left(l_{1}, l_{2}, w_{1}, w_{2}\right)=\frac{\left[\left(l_{2}-l_{1}\right)\left(3-l_{1}-l_{2}\right) t+w_{1}-w_{2}\right]^{2}}{18\left(l_{2}-l_{1}\right) t}
\end{aligned}
$$

In the third stage, each upstream firm sets its price at the rival's transportation cost if its own cost is lower than its rival's. ${ }^{12}$ The wholesale prices set by $U_{j}$ are as follows:

$$
w_{1 j}^{o o}=\max \left\{\tau\left(-\frac{1}{2}-l_{1}\right)^{2}, \tau\left(\frac{1}{2}-l_{1}\right)^{2}\right\}, w_{2 j}^{o o}=\max \left\{\tau\left(-\frac{1}{2}-l_{2}\right)^{2}, \tau\left(\frac{1}{2}-l_{2}\right)^{2}\right\} .
$$

Following the results of Matsushima (2004), we only consider a subgame in which $l_{1} \leq 0$ and $l_{2} \geq 0$. In the subgame, $U_{A}$ and $U_{B}$ supply to $D_{1}$ and $D_{2}$ respectively, and set their wholesale prices at

$$
w_{1 A}^{o o}=\tau\left(\frac{1}{2}-l_{1}\right)^{2}, \quad w_{2 B}^{o o}=\tau\left(-\frac{1}{2}-l_{2}\right)^{2} .
$$

Using Equations (15), (16), and (17), we obtain the maximization problems of the downstream firms in the second stage:

$$
\begin{aligned}
& \max _{l_{1}} \pi_{1}^{o o}\left(l_{1}, l_{2}\right)=\frac{\left[\left(l_{2}-l_{1}\right)\left(3+l_{1}+l_{2}\right) t+\left(1-l_{1}+l_{2}\right)\left(l_{1}+l_{2}\right) \tau\right]^{2}}{18\left(l_{2}-l_{1}\right) t}, \\
& \max _{l_{2}} \pi_{2}^{o o}\left(l_{1}, l_{2}\right)=\frac{\left[\left(l_{2}-l_{1}\right)\left(3-l_{1}-l_{2}\right) t-\left(1-l_{1}+l_{2}\right)\left(l_{1}+l_{2}\right) \tau\right]^{2}}{18\left(l_{2}-l_{1}\right) t} .
\end{aligned}
$$

The first-order conditions lead to the following lemma:

Lemma 2 When both downstream firms choose outsourcing, the following location pattern is an equilibrium outcome:

$$
l_{1}^{o o}=-\frac{3-2 \mu}{4(1+\mu)}, l_{2}^{o o}=\frac{3-2 \mu}{4(1+\mu)} .
$$

At the equilibrium outcome, each firm's profit is

$$
\pi_{i}^{o o}=\frac{3-2 \mu}{4(1+\mu)} t .
$$

Each firm's profit when $\mu=0$ is $\left.\pi_{i}^{o o}\right|_{\mu=0}=3 t / 4 . \pi_{i}^{o o}$ is strictly decreasing in $\mu$.

\footnotetext{
12 As noted by Matsushima (2004), it is also possible that when $\tau$ is large enough, an upstream firm optimally sets its wholesale price below its rival's transportation cost. However, this situation does not appear within the parameter ranges wherein our main propositions hold.
} 
As discussed in the previous subsection, each outsourcing firm has an incentive to move toward the center to reduce its input price $\left(\right.$ see $w_{i j}^{o o}$ in $\left.(17)\right)$. The force is stronger when the per unit transportation cost of each upstream firm, $\mu(=\tau / t)$, is larger. In fact, $l_{i}^{o o}$ decreases with $\mu$, leading to tougher downstream competition. As a result, $\pi_{i}^{o o}$ monotonically decreases with $\mu$. Although outsourcing works as a credible driver to locate closer to the center, it can accelerate downstream competition.

\subsection{The Insourcing-Insourcing Case}

In the last stage, the downstream firm, $i$, decides its price by solving the following optimization problem:

$$
\max _{p_{i}} \pi_{i}^{i i}\left(p_{1}, p_{2}, l_{1}, l_{2}\right) \equiv p_{i} Q_{i}\left(p_{1}, p_{2}, l_{1}, l_{2}\right)
$$

The equilibrium prices are as follows:

$$
p_{1}^{i i}\left(l_{1}, l_{2}\right)=\frac{\left(l_{2}-l_{1}\right)\left(3+l_{1}+l_{2}\right) t}{3}, p_{2}^{i i}\left(l_{1}, l_{2}\right)=\frac{\left(l_{2}-l_{1}\right)\left(3-l_{1}-l_{2}\right) t}{3}
$$

Substituting $p_{1}^{i i}\left(l_{1}, l_{2}\right)$ and $p_{2}^{i i}\left(l_{1}, l_{2}\right)$ in $(21)$ into Equation (20), we obtain the maximization problems of the downstream firms in the second stage:

$$
\begin{aligned}
& \max _{l_{1}} \pi_{1}^{i i}\left(l_{1}, l_{2}\right) \equiv \frac{\left(l_{2}-l_{1}\right)\left(3+l_{1}+l_{2}\right)^{2} t}{18}, \\
& \max _{l_{2}} \pi_{2}^{i i}\left(l_{1}, l_{2}\right) \equiv \frac{\left(l_{2}-l_{1}\right)\left(3-l_{1}-l_{2}\right)^{2} t}{18} .
\end{aligned}
$$

The first-order conditions lead to the following lemma:

Lemma 3 When both downstream firms choose insourcing, the following location pattern is an equilibrium outcome:

$$
l_{1}^{i i}=-\frac{3}{4}, l_{2}^{i i}=\frac{3}{4} .
$$

At the equilibrium outcome, each firm's profit is

$$
\pi_{i}^{i i}=\frac{3 t}{4}
$$


This result is equivalent with that of Tabuchi and Thisse (1995).

From Lemmas 2 and 3, we have the following result:

Proposition 2 For any positive $\mu, \pi_{i}^{i i}>\pi_{i}^{o o}$. That is, the profits when both downstream firms' choose insourcing are strictly larger than when they select outsourcing.

Interestingly, although outsourcing provides relative advantages (including location and quality) to a downstream firm employing it, these advantages are completely cancelled out if both downstream firms employ outsourcing. As a result, outsourcing can merely give rise to the prisoner's dilemma.

\subsection{Sourcing Patterns in Equilibrium}

In the first stage, each downstream firm simultaneously decides the sourcing pattern. Although we need to derive the threshold values of $\mu$ in which $\pi_{i}^{i i}=\pi_{1}^{o i}$ and $\pi_{2}^{o i}=\pi_{i}^{o o}$, we cannot explicitly derive these values of $\mu$ owing to the mathematical complexity. We therefore check these values numerically. Let $\mu_{i i}(\alpha)$ and $\mu_{o o}(\alpha)$ be the threshold values of $\mu$ such that $\pi_{i}^{i i}=\pi_{1}^{o i}$ and $\pi_{2}^{o i}=\pi_{i}^{o o}$ respectively. Under the notation, we have the following relations:

- $\pi_{i}^{i i}<\pi_{1}^{o i}$ if and only if $\mu<\mu_{i i}(\alpha)$. That is, given that one of the two downstream firms insources, the other prefers outsourcing if and only if $\mu<\mu_{i i}(\alpha)$.

- $\pi_{2}^{o i}<\pi_{i}^{o o}$ if and only if $\mu<\mu_{o o}(\alpha)$. That is, given that one of the two downstream firms outsources, the other prefers outsourcing if and only if $\mu<\mu_{i i}(\alpha)$.

To secure the possibility that $\pi_{i}^{i i} \geq \pi_{1}^{o i}$, we impose the upper value of $\alpha$ at 0.129 as in Assumption 2. We set $\alpha$ at 0.01 intervals and check the threshold values of $\mu$ at each $\alpha$. The result is summarized in Table 1 . The relation between the profits and $\mu(=\tau / t)$ is summarized in Figure 1.

[Table 1 and Figure 1 about here] 
We find that $\mu_{i i}(\alpha)>\mu_{o o}(\alpha)$ for any $\alpha .^{13}$ From the argument, we obtain the following proposition.

Proposition 3 Under the parameter restrictions imposed above, the equilibrium sourcing pattern is summarized as follows:

1. Both downstream firms choose outsourcing if and only if $\mu \leq \mu_{o o}(\alpha)$.

2. One downstream firm chooses outsourcing while the other chooses insourcing if and only if $\mu_{o o}(\alpha) \leq \mu \leq \mu_{i i}(\alpha)$.

3. Both downstream firms choose insourcing when $\mu_{i i}(\alpha) \leq \mu$.

From Proposition 3, when the input procurement condition is loose ( $\tau$ is small enough), both downstream manufacturers choosing outsourcing appears as an equilibrium outcome. This finding is also supported by some empirical studies demonstrating that geographical agglomeration reduces costs of input delivery and thus makes downstream manufacturers more willing to outsource their input production (Holl, 2008; Belso-Martinez, 2010; Figueiredo et al., 2010).

From Propositions 2 and 3, we have the following corollary:

Corollary 1 When $\mu<\mu_{o o}(\alpha)$, although both downstream firms would be better off insourcing, both still choose outsourcing.

\section{Extension}

We have considered the situation in which outsourcing benefits a downstream firm through a quality advantage, $e_{i}=\alpha t$. We now consider another possible benefit of outsourcingeliminating/reducing fixed costs, $F$, necessary for input production. We can directly apply the result in the previous section to the new situation by substituting $e_{i}=0$ and introducing fixed costs $F$ for insourcing. We show the result of outsourcing decisions in graphical terms in

${ }^{13}$ This relation holds true even if we set $\alpha$ at 0.001 intervals and check the threshold values of $\mu$ at each $\alpha$. 
Figure 2. The equilibrium property in the new situation is similar to that in the main model in the sense that the higher the value of $\mu$, the stronger the tendency to insource.

\section{[Figure 2 about here]}

As in the previous section, we set $F$ at 0.01 intervals and check the threshold values of $\mu$ at each $F$. The result is summarized in Table 2. The relation between the profits and $\mu$ is summarized in Figure 3.

[Table 2 and Figure 3 about here]

We find that $\mu_{i i}(F)>\mu_{o o}(F)$ for any $F$, and there always exists the parameter range wherein prisoner's dilemma occurs. ${ }^{14}$ From the argument, we obtain the following proposition.

Proposition 4 Under the parameter restrictions imposed above, the equilibrium sourcing pattern is summarized as follows:

1. Both downstream firms choose outsourcing if and only if $\mu \leq \mu_{o o}(F)$.

2. One downstream firm chooses outsourcing while the other chooses insourcing if and only if $\mu_{o o}(F) \leq \mu \leq \mu_{i i}(F)$.

3. Both downstream firms choose insourcing when $\mu_{i i}(F) \leq \mu$.

\section{Concluding Remarks}

In this study, we demonstrate the strategic perils of outsourcing. We consider a linear city wherein two upstream suppliers' locations are exogenously given while two downstream manufacturers endogenously determine their respective location and sourcing pattern - outsourcing or insourcing. We show that under outsourcing, although each downstream manufacturer will choose the supplier whose inputs are more compatible, it tends to locate closer to the other supplier for better outside options, and thus obtains input products at a lower wholesale

\footnotetext{
${ }^{14}$ This relation holds true even if we set $F$ at 0.001 intervals and check the threshold values of $\mu$ at each $F$.
} 
price. This feature may create a prisoner's dilemma: both downstream manufacturers choose outsourcing and thus locate too close to each other, leading to overly intense downstream competition.

For tractability, we assume that the final products' quality level under outsourcing is given exogenously. Even though endogenizing the quality level may make our model more comprehensive, we find the process to be too complicated technically. Because our results are robust as long as the final products' quality takes positive values, we believe endogenizing the quality level would not lead to further contributions.

\section{References}

Ahmadjian, C.L., J.R. Lincoln. 2001. Keiretsu, governance, and learning: Case studies in change from the Japanese automotive industry. Organization Science 12(6), 683-701.

Belso-Martinez, J.A. 2010. Outsourcing decisions, product innovation and the spatial dimension: Evidence from the Spanish footwear industry. Urban Studies 47(14), 3057-3077.

Bonaccorsi, A., P. Giuri. 2001. The long-term evolution of vertically-related industries. International Journal of Industrial Organization 19(7), 1053-1083.

Desai, P.S. 2001. Quality segmentation in spatial markets: when does cannibalization affect product line design? Marketing Science 20(3), 265-283.

Eaton, B.C., N. Schmitt. 1994. Flexible manufacturing and market structure. American Economic Review 84(4), 875-888.

Figueiredo, O., P. Guimarães, D. Woodward. 2010. Vertical disintegration in Marshallian industrial districts. Regional Science and Urban Economics 40(1), 73-78.

Gilbert, S.M., Y. Xia, G. Yu. 2006. Strategic outsourcing for competing OEMs that face cost reduction opportunities. IIE Transactions 38(11), 903-915.

Grossman, G.M., E. Helpman. 2002. Integration versus outsourcing in industry equilibrium. Quarterly Journal of Economics 117(1), 85-120.

Guo, L. 2006. Consumption flexibility, product configuration, and market competition. Marketing Science 25(2), 116-130. 
Hauser, J.R. 1988. Competitive price and positioning strategies. Marketing Science 7(1), $76-91$.

Holl, A. 2008. Production subcontracting and location. Regional Science and Urban Economics 38(3), 299-309.

Kim, H., K. Serfes. 2006. A location model with preference for variety. Journal of Industrial Economics 54(4), 569-595.

Kuksov, D. 2004. Buyer search costs and endogenous product design. Marketing Science 23(4), 490-499.

Liu, Y., R.K. Tyagi. 2011. The benefits of competitive upward channel decentralization. Management Science 57(4), 741-751.

Liu, Y., R.K. Tyagi. 2016. Outsourcing to convert fixed costs into variable costs: A competitive analysis. forthcoming in International Journal of Research in Marketing. http://dx.doi.org/10.1016/j.ijresmar.2016.08.002

Matsushima, N. 2004. Technology of upstream firms and equilibrium product differentiation. International Journal of Industrial Organization 22(8-9), 1091-1114.

Matsushima, N. 2009. Vertical mergers and product differentiation. Journal of Industrial Economics 57(4), 812-834.

Marjit S., A. Mukherjee. 2008. Profit reducing international outsourcing. The Journal of International Trade $\&$ Economic Development 17(1), 21-35.

Meza, S., M. Tombak. 2009. Endogenous location leadership. International Journal of Industrial Organization 27(6), 687-707.

Moorthy, K.S. 1988. Product and price competition in a duopoly. Marketing Science 7(2), $141-168$.

Norman, G., J.-F. Thisse. 1999. Technology choice and market structure: strategic aspect of flexible manufacturing. Journal of Industrial Economics 47(3), 345-372.

Novak, S., S.D. Eppinger. 2001. Sourcing by design: Product complexity and the supply chain. Management Science 47(1), 189-204.

Sajeesh, S. 2016. Influence of market-level and inter-firm differences in costs on product positioning and pricing. Applied Economics Letters 23(12), 888-896. 
Sajeesh, S., J.S. Raju. 2010. Positioning and pricing in a variety seeking market. Management Science 56(6), 949-961.

Shy, O., R. Stenbacka. 2003. Strategic outsourcing. Journal of Economic Behavior EG Organization 50(2), 203-224.

Tabuchi, T., J.-F. Thisse. 1995. Asymmetric equilibria in spatial competition. International Journal of Industrial Organization 13(2), 213-227.

Tyagi, R.K. 2000. Sequential product positioning under differential costs. Management Science 46(7), 928-940.

Tyagi, R.K. 2001. Cost leadership and pricing. Economics Letters 72(2), 189-193.

Ulrich, K.T., D.J. Ellison. 2005.Beyond make-buy: Internalization and integration of design and production. Production and Operations Management 14(3), 315-330.

Xiang, Y., M. Sarvary. 2007. News consumption and media bias. Marketing Science 26(5), $611-628$.

Xiao, T., Y. Xia, G.P. Zhang. 2014. Strategic outsourcing decisions for manufacturers competing on product quality. IIE Transactions 46(4), 313-329.

Zhang, J. 2011. The perils of behavior-based personalization. Marketing Science 30(1), $170-186$.

Zhu, K., R.Q. Zhang, F. Tsung. 2007. Pushing quality improvement along supply chains. Management Science 53(3), 421-436. 
Table 1: Threshold values of $\mu$

\begin{tabular}{l|c|c|c|c|c|c}
\hline$\mu \backslash \alpha$ & 0.01 & 0.02 & 0.03 & 0.04 & 0.05 & 0.06 \\
\hline$\mu_{i i}(\alpha)$ & 0.017 & 0.034 & 0.054 & 0.075 & 0.098 & 0.125 \\
\hline$\mu_{o o}(\alpha)$ & 0.016 & 0.033 & 0.050 & 0.085 & 0.085 & 0.104 \\
\hline \hline$\mu \backslash \alpha$ & 0.07 & 0.08 & 0.09 & 0.10 & 0.11 & 0.12 \\
\hline$\mu_{i i}(\alpha)$ & 0.154 & 0.188 & 0.228 & 0.277 & 0.341 & 0.437 \\
\hline$\mu_{o o}(\alpha)$ & 0.122 & 0.141 & 0.161 & 0.180 & 0.201 & 0.221 \\
\hline
\end{tabular}


Table 2: Threshold values of $\mu$

\begin{tabular}{l|c|c|c|c|c|c}
\hline$\mu \backslash F$ & 0.01 & 0.02 & 0.03 & 0.04 & 0.05 & 0.06 \\
\hline$\mu_{i i}(F)$ & 0.0248 & 0.0513 & 0.0799 & 0.1107 & 0.1442 & 0.1810 \\
\hline$\mu_{o o}(F)$ & 0.0246 & 0.0504 & 0.0776 & 0.1062 & 0.1364 & 0.1683 \\
\hline \hline$\mu \backslash F$ & 0.07 & 0.08 & 0.09 & 0.10 & 0.11 & 0.12 \\
\hline$\mu_{i i}(F)$ & 0.2218 & 0.2675 & 0.3196 & 0.3806 & 0.4545 & 0.5500 \\
\hline$\mu_{o o}(F)$ & 0.2020 & 0.2376 & 0.2754 & 0.3155 & 0.3580 & 0.4033 \\
\hline
\end{tabular}




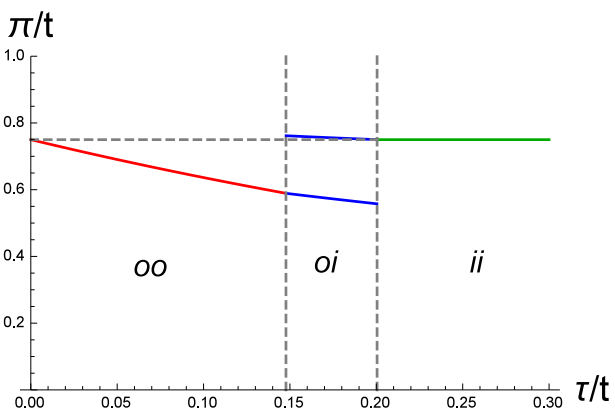

(a) The equilibrium profits

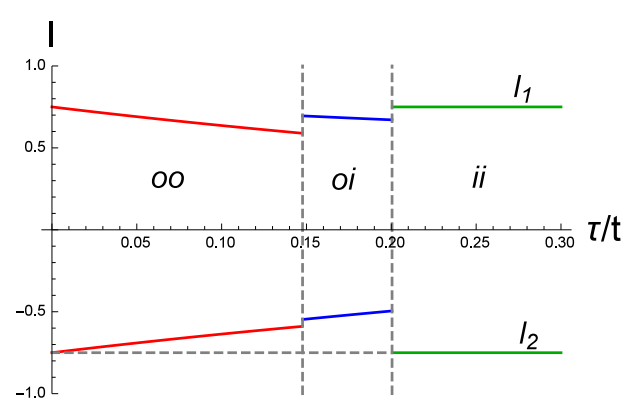

(b) The downstream firm's equilibrium locations

Figure 1: The equilibrium outcomes $(\alpha=1 / 12)$ 

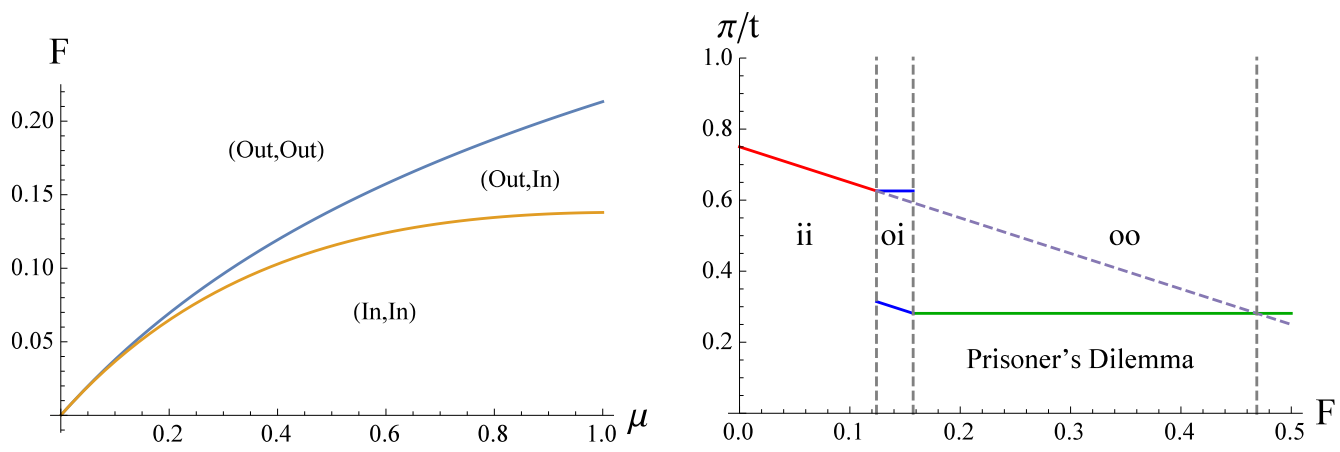

Figure 2: Equilibrium outcomes and equilibrium profits ( $\mu=0.6$ at the right-hand side figure) 

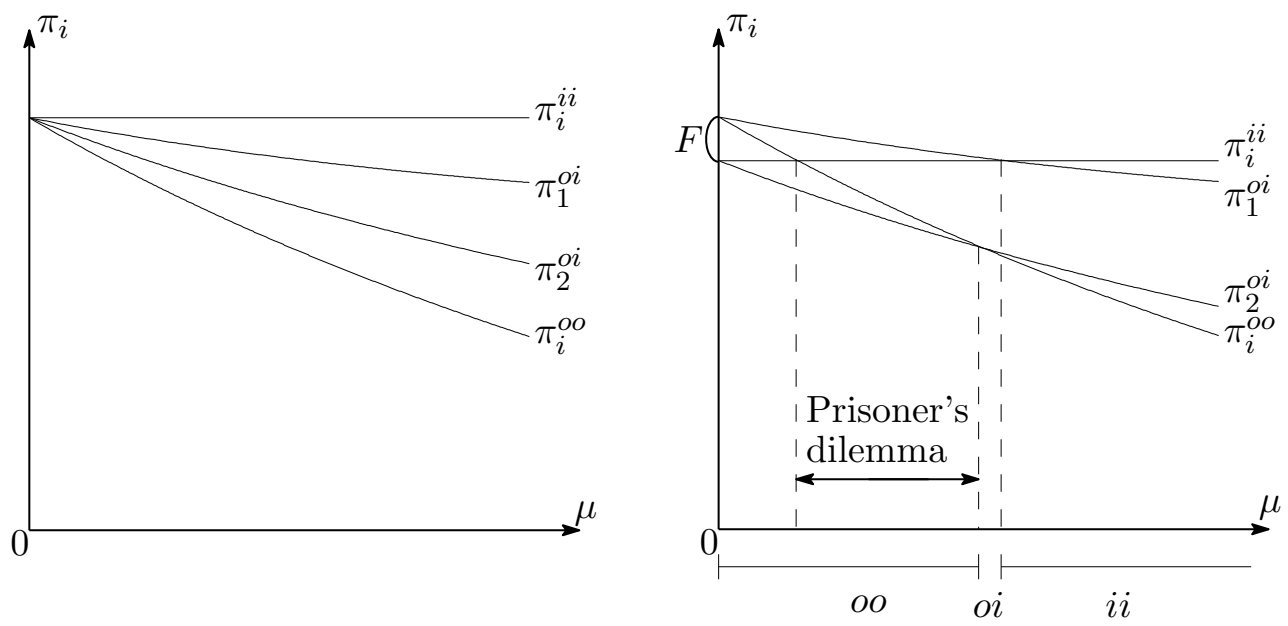

$(F=0)$

$(F=1 / 16)$

Figure 3: Equilibrium profits $(F=0$ and $F=1 / 16)$ 